\title{
Socket Sealing with a new xenogenic porcine \\ collagen matrix: a prospective cohort study
}

IMPLANT THERAPY

OUTCOMES, PERI-IMPLANT

BIOLOGY ASPECTS
Department of Biomedical, Surgical and Dental Sciences, University of Milan, ASST Santi Paolo e Carlo, Clinical Surgery Unit (Head: Prof. Matteo Chiapasco)

\section{Abstract}

The study analyzes, through clinical, histological and aesthetic examination, the use of a 3D collagen matrix (Mucoderm $\AA$, Botiss Dental, Germany) as a socket sealing material, to lead the regeneration of new keratinized tissue over post-extractive sockets filled with a xenogenic bone substitute or with an immediate submerged implant.
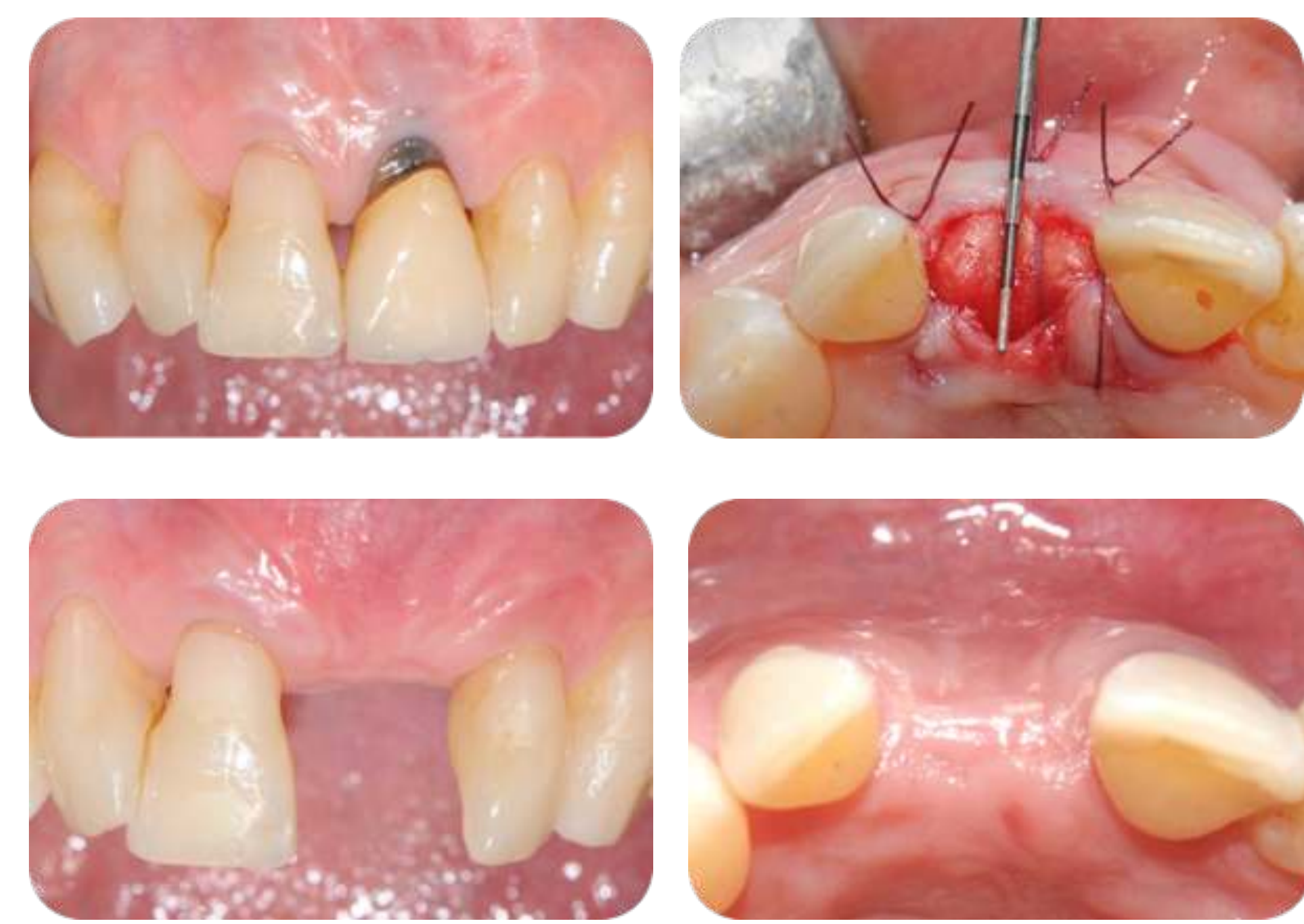

Background and Aim

Despite the ongoing debate about the meaning of keratinized gingiva, most papers agree that a sufficiently broad band of keratinized tissue exert a positive effect on long-term prognosis and maintain of dental implants.

The recent introduction of xenogenic collagen matrixes further expanded the clinical alternatives in the management of soft tissues healing during pre-implant or peri-implant regenerative procedures.

The aim of this prospective cohort study is to test the performance of a new xenogenic collagen matrix (Mucoderm $\AA$, Botiss Dental, Germany) as a socket sealing material, to allow second-intention healing of postextractive sockets filled with a xenogenic bone substitute or with an immediate submerged implant.

\section{Methods and Materials}

10 patients (4 males and 6 females - mean age: 53.2 years) were recruited, presenting with a single-rooted tooth scheduled for extraction, because of unsalvageable endo-perio lesions or vertical root fractures.

After atraumatic tooth removal, the post-extractive alveolus received either a socket preservation procedure or an immediate submerged implant. Demineralized bovine bone mineral integrated in a $10 \%$ collagen matrix (Bio-Oss Collagen $®$, Geistlich Pharma, Switzerland) was used as a socket preservation material or to fill the gap between the implant surface socket preservation material or to
and the bony walls of the alveolus.

In both cases, the gingival margins of the alveolus were sealed with a xenogenic collagen matrix (Mucoderm $\AA$, Botiss Dental, Germany) Through $5 / 0$ monofilament sutures, the matrix was gently stabilized subperiosteally under the palatal and buccal gingival margins of the subperiosteally under the palatal and buccal gingival margins of the
socket for $2 / 3$ of its surface, whether $1 / 3$ remained exposed for second

The following parameters were evaluated:

a) exposed surface of the matrix at the end of surgery (TO)

b) soft tissue healing at 1, 4, 6, and 8 weeks from surgery (T1-4);

c) aesthetic performance provided by the socket sealing material, quantified deriving the colorimetric score $\Delta \mathrm{E}$ between the regenerated site and the surrounding gingiva, 8 weeks after surgery (T4);

d) histological aspect of gingiva samples, harvested 20 weeks after surgery (T5) from the regenerated area.

\section{Results}

a) the mean postoperative exposure area of the matrix was $26,25 \mathrm{~mm} 2$ (14,2 to $38,84 \mathrm{~mm} 2)$;

b) 8 weeks after surgery (T4), full wound closure was achieved in 9 out of 10 sites with healthy keratinized tissue. A single patient (\#3) did not achieve full wound closure at T4, starting from the highest postoperative matrix exposure rate of the cohort (38,84 mm2);

c) the mean colorimetric score $\Delta \mathrm{E}$ between the regenerated site and the surrounding gingiva at 14 was 3,76 ( 3 to 6,55 ). Seven out of 10 patients reported an excellent aesthetic integration of the matrix ( $\Delta$ score < 37). Two patients reported an acceptable integration of the matrix ( $\triangle E=3,95$ and 4,28 ) and only a single patient (\#3) reported a limited aesthetic result $(\Delta \mathrm{E}=6,55)$ at $\mathrm{T} 4$;

d) the histological evaluation of gingiva samples at T5 reveled the presence of healthy keratinized gingival tissue, with no signs of aberrations or anomalies.
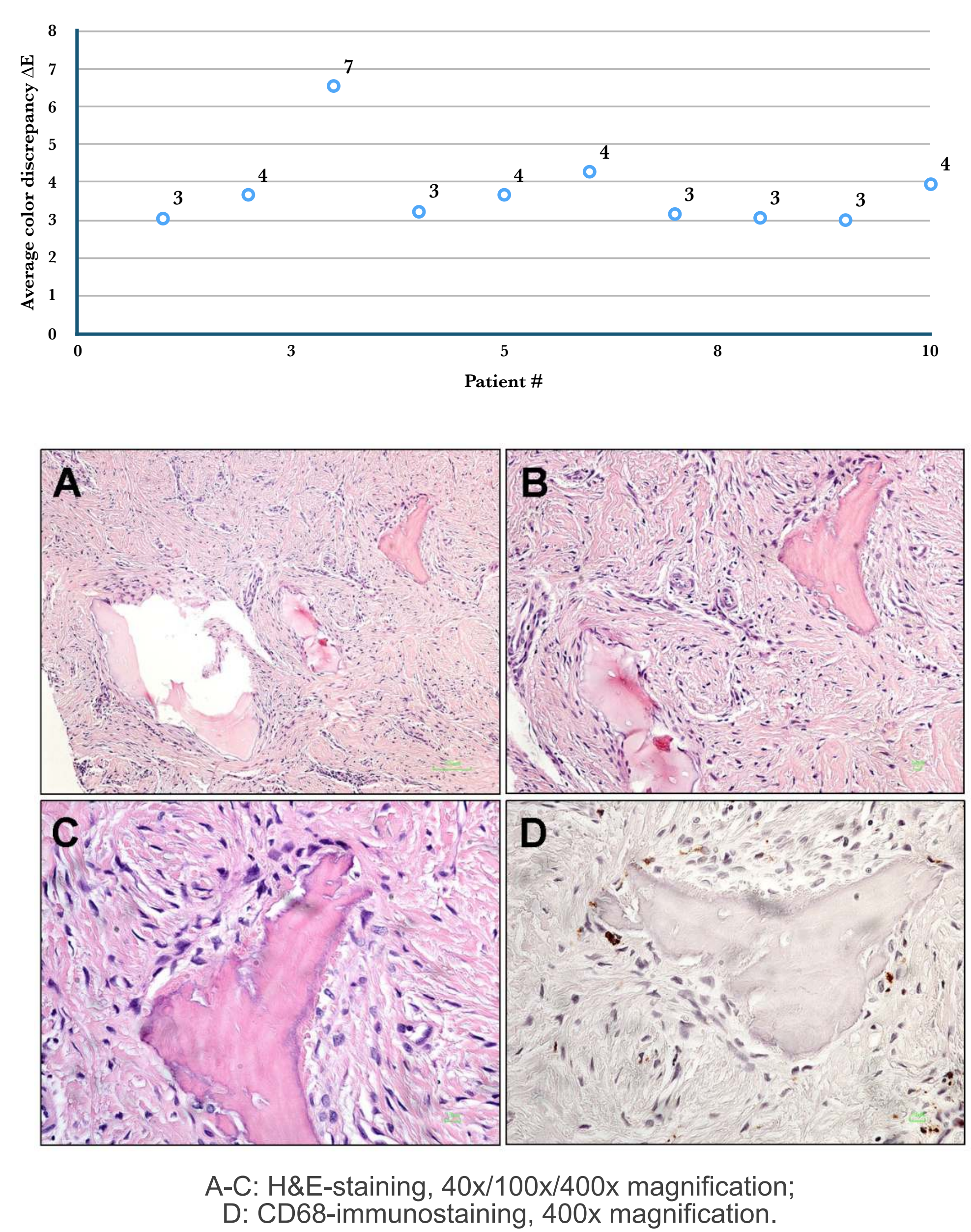

\section{Conclusions}

Preliminary results from this study suggest that this new xenogenic porcine-derived collagen matrix could represent a valuable alternative to allow second intention healing of post-extractive sockets filled with a xenogenic bone substitute or with an immediate submerged implant.

\section{References}

Chung DM, Oh TJ, Shotwell JL, Misch CE, Wang HL. Significance of keratinized mucosa in maintenance of dental imp

Grusovin MG, Coulthard P, Worthington HV, Esposito M. Maintaining and recovering soft tissue health
around dental implants: a Cochrane systematic review of randomised controlled clinical trials. Eur J Ora Implantol. 2008; 1(1): 11-22 Sanz M, Lorenzo R, Aranda JJ, Martin C, Orsini M. Clinical evaluation of a new collagen matrix
(Mucograft prototype) to enhance the width of keratinizzed tissue in patients with fixed prosthetic
restorations: a randomized prospective clinical trial. J Clin Periodontol. 2009 Oct:36(10):868-76. Zigdon H, Machtei EE. The dimensions of keratinized mucosa around implants affect clinical and Esposito M, Maghaireh H, Grusovin MG, Ziounas I, Worthington HV. Soft tissue management for dental
mplants: what are the most effective techniques? A Cochrane systematic review. Eur J Oral Implantol 2012 Autumn:5(3):221-38 